\title{
PRODUCT MIX OPTIMIZATION BASED ON MONTE CARLO SIMULATION: A CASE STUDY
}

\author{
Janekova, J. ; Fabianova, J. ${ }^{* *, \#}$; Izarikova, G. ${ }^{* * *}$; Onofrejova, D. ${ }^{*} \&$ Kovac, J. \\ * Institute of Management, Industrial and Digital Engineering, Faculty of Mechanical Engineering, \\ Technical University of Kosice, Park Komenskeho 9, 04200 Kosice, Slovakia \\ ** Institute of Logistics, Faculty of Mining, Ecology, Process Control and Geotechnology, \\ Technical University of Kosice, Letna 9, 04200 Kosice, Slovakia \\ **** Department of Applied Mathematics and Informatics, Faculty of Mechanical Engineering, \\ Technical University of Kosice, Letna 9, 04200 Kosice, Slovakia \\ E-Mail: jaroslava.janekova@tuke.sk,jana.fabianova@tuke.sk, gabriela.izarikova@tuke.sk, \\ daniela.onofrejova@tuke.sk, jozef.kovac@tuke.sk (" Corresponding author)
}

\begin{abstract}
Simulations are widely used in manufacturing system design, production planning and decision making. The aim of this paper is to present the possibility of using Monte Carlo simulations in the production plan optimizing and in the project risk management. Optimization is accomplished through two different approaches which principles and results are mutually compared. According to the first approach, production optimization is performed via a deterministic model using the Generalized Reduced Gradient algorithm. The second approach is based on the stochastic model. The optimized production plan is submitted to risk analysis. Two approaches are demonstrated in order to reduce the rate of risk. The first way is modifying the production plan to increase the forecast reliability; the second approach is limiting the uncertainty of key variables. The detailed methodology enables implementing presented approaches in solving various optimization tasks.

(Received in December 2017, accepted in March 2018. This paper was with the authors 1 week for 1 revision.)
\end{abstract}

Key Words: Investment Efficiency, Production Planning, Computer Simulation, Optimisation

\section{INTRODUCTION}

Planning and production optimisation is an important step in the preparation of production. In the case of the key production capacities and critical nodes of the production process, the optimization of the production program is of paramount significance. The importance of the problem of planning and production capacities utilization is also evidenced by a number of reviews and scientific papers dealing with this issue. A comprehensive review and critique on the current production - distribution planning and optimisation literature was performed by [1]. A problem of a flexible production planning was addressed by [2], and the topic of the production system productivity was dealt by [3]. Production planning solves a great variety of problems, but the product mix problem seems one of the most important problems in production systems. An integer programming approach for process planning for mixed-model parts was applied in [4]. The paper by [5] addressed the issues of time bucket selection, mix optimization and bottleneck-based planning using a decision software system based on integer linear programming techniques and a heuristic procedure. The work by [6] was devoted to the evaluation of production processes in mass production. An analytic hierarchy process and analytic network process approaches were taken to obtain optimal product mixes in [7]. An approach often used in production planning is the theory of constraints (TOC). One application of the theory is product mix decision. Algorithms to determine the product mix under the theory of constraints were presented by $[8,9]$. On the other hand [10] discussed the inefficiency of the traditional TOC algorithm in handling the multiple bottleneck problem. In this paper, all bottlenecks were used in order to determine the aggregated priority of each product, and a multi-criteria decision-making approach was proposed for product mix 
problem with interval parameters. Linear programming and mixed integer programming models for the production and capacity planning problems with uncertainty in demand were proposed by [11]. The large number of requirements that need to be met when planning and also their varying nature are the reason for using simulation. Many scientific papers presented the use of various simulation techniques in decision-making processes. A systematic literature review on the use of discrete event simulation for manufacturing system design and operation problems was elaborated by [12]. A simulation-based framework that allowed for modelling the behaviour of the market demand and the production system was introduced by [13]. Application of computer simulation for improvement of production logistics' efficiency was presented in [14]. A simulation optimization approach to develop a decision support tool to aid in strategic and operational decision-making was employed in [15]. The study by [16] aimed to integrate customer relationship management and production planning and control approaches in order to use manufacturing resources more effectively in satisfying customers. Simulations maintain an irreplaceable role also in optimization and solving of problems with endogenous uncertainty. In the research by [17], a simulation optimization approach was employed to develop a decision support tool for strategic and operational decision-making. A metamodeling approach, which integrates discrete-event simulation, adaptive statistical methods and analytical queueing analysis, was proposed in [18]. A hybridization of Pattern Search method and Simulated Annealing (SA) were incorporated in the optimization process by [19]. The real strength of SA approach was tested in a case study on industrial production planning. In the paper of [20], a meta-heuristic algorithm "Imperialist Competitive Algorithm" was applied to solve the integrated product mix-outsourcing optimization problem. Other applications of simulations are described in [21, 22]. One of the most commonly used simulation techniques is Monte Carlo. The use of Monte Carlo samplingbased methods for stochastic optimization problems was surveyed by [23]. Application of multi-objective Monte Carlo optimization for optimal location selection of new manufacturing sites was presented by [24]. Simulation experiments have particular importance in situations where an enterprise decides on investment projects. Investing in real capital means new opportunities for the company and at the same time brings new risks. Profitability and rapid return on investment also depend on the production plan that ensures reliable and sufficient cash flow. An analysis of investment project risks utilizing Monte Carlo simulations was performed in [25].

The aim of this paper is to point out the possibility of using Monte Carlo simulations in the process of optimizing the production plan. The goal of optimisation is to maximize the economic efficiency of the investment, measured by the Net Present Value $(N P V)$ financial indicator. The secondary objective is to present the use of simulations in the risk management of the investment process. Two approaches towards optimizing the production program are demonstrated in the case study. First approach applies a non-linear GRG algorithm to optimisation. This approach does not consider stochastic character of input variables and does not use simulations. The second approach implements the stochastic character of inputs into product plan optimisation using the Monte Carlo simulation. Subsequent analysis of the simulation results reveals the hidden risk factors and the possibilities to reach the goal. The detailed methodology and step-by-step approach enable implementing both presented approaches in solving any optimization tasks, not just in the field of production planning.

\section{MATERIALS AND METHODS}

\subsection{Case study description}

The case study is focused on the mass production of paper napkins ( $\mathrm{A}$ - white, $\mathrm{B}$ - coloured and $\mathrm{C}$ - patterned). At present, production is performed on nine production lines for the 
domestic and foreign market. The production volume has a growing trend and a company has to solve a case of insufficient production capacity. In terms of time utilisation, production lines are used at 70-75\%. The highest downtime ratio generates technological downtime caused by a changeover: change in format (e.g., 1/4, 1/8 folding) and blocks, cleaning of machines when switching to another pattern and the related production start. The insufficient production capacity in the company is partially solved by outsourcing - external production especially of white napkins. This leads to the dependence of the company on the residual capacities and deadlines of external producers, the economically unprofitable production, a need to transfer the know-how to an external producer due to the production of products with identical parameters, and the inefficient planning of production scenarios on their own production lines intended for the production of white napkins (recurrent changeover of formats due to a supply time pressure and associated downsizing of line performance). These facts result into the need for a new production line eliminating the external production of white napkins (at least 700 tons per year - agreed long-term orders) and using the remaining residual capacity of the line to expand the production of coloured and patterned products with an emphasis on maximizing the Net Present Value $(N P V)$. The procedure for solving the problem is recorded in Fig. 1.

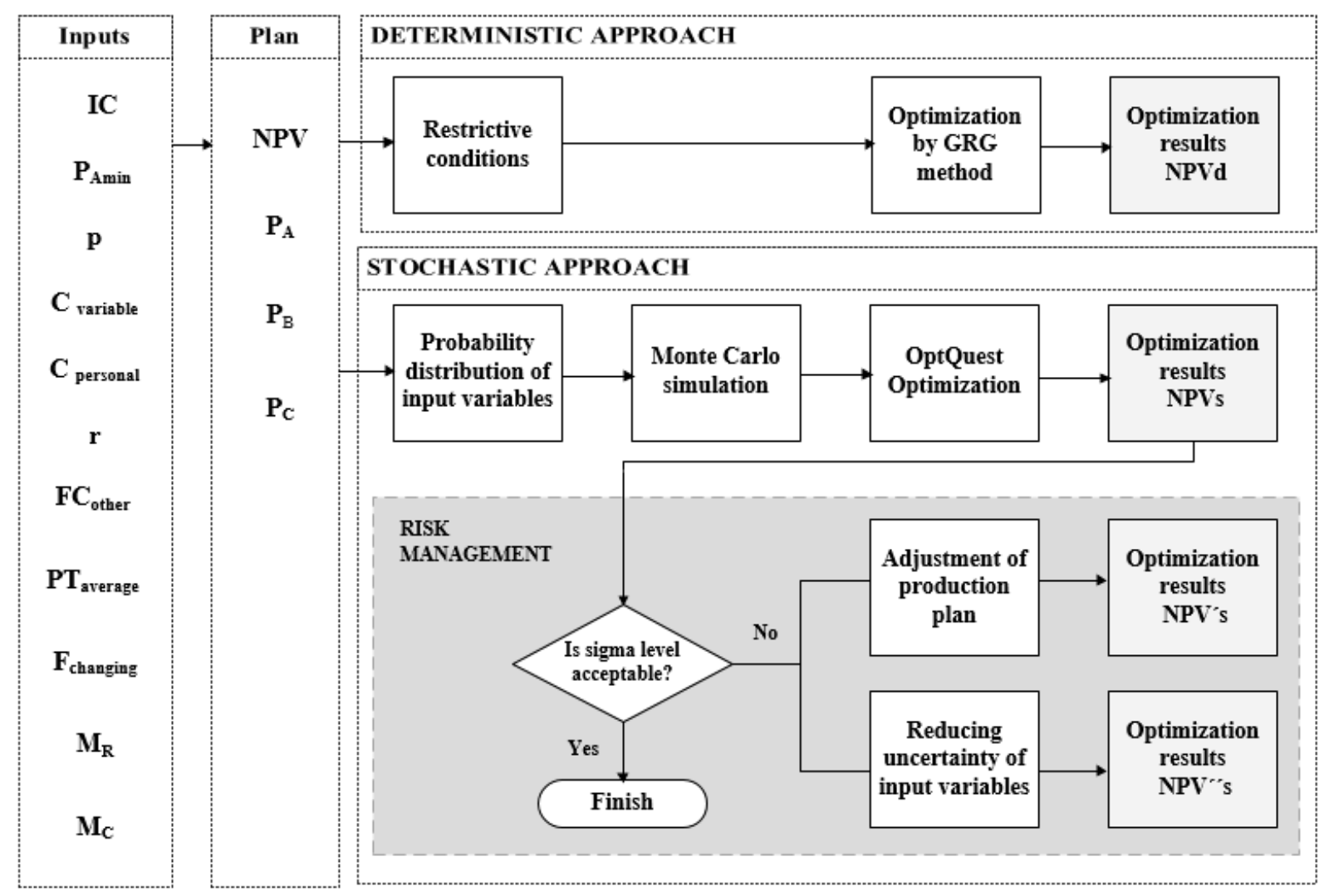

Legend: $\mathrm{P}_{\mathrm{Amin}}$ - production, $\mathrm{p}$ - price, $\mathrm{C}_{\text {variable }}-$ variable costs, $\mathrm{C}_{\text {personal }}$ - personal expenses, $\mathrm{r}$ - rejects, $\mathrm{FC}_{\text {other }}$ - fixed costs other, $\mathrm{PT}_{\text {average }}$ - average production time, $\mathrm{F}_{\text {changing }}$ - format changing, $\mathrm{M}_{\mathrm{c}}$ - machine cleaning, $\mathrm{M}_{\mathrm{r}}$ - machine repairs, IC - investment costs.

Figure 1: Schematic procedure for the problem solution.

\section{$2.2 N P V$ analysis}

The economic efficiency of an investment project is assessed using the $N P V$ financial criterion for an economic lifetime of eight years. The calculation is made according to the Eq. (1) $[26]:$ 


$$
N P V=\sum_{n=1}^{N} \frac{C F_{n}}{(1+d)^{n}}-I C
$$

where $C F_{\mathrm{n}}$ is cash flow in year $n, I C$ investment costs, $N$ life of the investment, $n$ number of years of life of the investment and $d$ discount rate.

The $N P V$ value is determined by the amount of annual cash flow from the investment and the amount of the disposable investment cost. For $C F$ value, only cash flow from an operating activity is taken into consideration, as the impact of the investment financing is taken into account when discounting, at a discount rate that includes the owner's risk, including the risk of the creditors. The relationship for predicting the annual $C F$ of the operating activity is expressed, as follows Eq. (2) [26]:

$$
C F_{n}=E B I T D A_{n} \cdot\left(1-T_{n}\right)+\left(D_{n} \cdot T_{n}\right)-\Delta N C W C_{n}
$$

where EBIT is earning before interest and tax, EBITDA earning before interest, tax, depreciation and amortization, $D$ depreciation, $T$ income tax rate, $N C W C$ non-cash working capital.

EBITDA is affected by production and sales activities that confirm the relationships Eqs. (3) to (5) for its annual forecast:

$$
\begin{gathered}
\operatorname{EBITDA}_{n}=\sum_{j=1}^{3} S_{n j}-\sum_{j=1}^{3} C_{n j} \\
S_{n j}=\left(p_{n j} \cdot P_{n j}\right)-\left(p_{n j} \cdot P_{n j} \cdot r_{j}\right) \\
C_{n j}=\left(\text { c }_{\text {variable }_{n j}} \cdot P_{n j}\right)+\left(C_{\text {personal }} \cdot 1.02^{n-1}\right)+(I C \cdot 0.03)
\end{gathered}
$$

where $S$ is sales, $p$ price, $P$ production, $r$ reject in $\% / 100, c_{\text {variable }}$ variable costs and $C_{\text {personal }}$ personal expenses, $j$ product range $(\mathrm{A}, \mathrm{B}, \mathrm{C}),(I C \cdot 0.03)$ other annual fixed costs.

The production is of a continuous nature. The annual production volume is determined by the annual operating time of the production line and the selected production plan. The value of the sales total is reduced by the price value of rejects.

\subsection{Simulation and optimization methods}

Simulation method Monte Carlo is based on a statistic approach, obtaining general characteristics based on multiple random experiments, which can be applied for description of a modelled phenomenon.

During simulation, values of random variables are substituted by generated large number of realizations of a given random variable, and then computed statistically.

Monte Carlo method procedure:

- Defining the objective (purpose of simulation).

- Data preparation and selection of a tool.

- Selection of key parameters of simulation - analysis of the problem.

- Determination of probability distribution of random variables. When developing an appropriate Monte Carlo model, very important step is to determine the correct constraints for each variable and the correct relationship among variables. Design of particular parametric model.

- Simulation of the model.

- Output from the model and results of the analysis.

To optimize the deterministic model of $N P V$ calculation, here the Generalized Reduced Gradient (GRG2) algorithm was used. GRG method is suitable for optimizing nonlinear problems. The method can find a local optimal solution for a non-convex model. Solving the 
problem based on gradients, GRG method finds a local optimum only on continuous functions, and only if there are no numerical problems or incorrect conditions.

To find the optimal solution for the stochastic model, the OptQuest was used. OptQuest is an optimisation tool based on the Scatter search methodology coupled with Tabu search strategies. OptQuest allows obtaining high quality solutions to problems defined in complex settings. OptQuest also checks for compliance with the constraints and requirements.

\section{RESULTS}

\subsection{Calculation of $N P V$ according to preliminary plan}

The preliminary production plan for the new production line consists of products A of volume 700 tonnes per year contractually agreed, and products B and C. Production of products B and $\mathrm{C}$ is planned in a ratio of $0.5: 0.5$ for the remaining part of the annual capacity of the production line. Line profitability is measured using $N P V$ value from the following input data (see Table I).

Table I: Input variables for $N P V$ calculation.

\begin{tabular}{|c|c|c|c|c|c|}
\hline \multirow{2}{*}{\multicolumn{2}{|c|}{ Input variables }} & \multirow{3}{*}{$\begin{array}{l}\text { Unit } \\
\text { t/year }\end{array}$} & \multicolumn{3}{|c|}{ Value for product } \\
\hline & & & $\mathbf{A}$ & B & $\mathbf{C}$ \\
\hline \multirow{6}{*}{ : } & Production volume & & 700 & - & - \\
\hline & Free production time of a machine & $\%$ & - & 50 & 50 \\
\hline & Average production time & $\mathrm{h} / \mathrm{t}$ & 6.0 & 8.5 & 7.5 \\
\hline & Price & EUR/t & 1,000 & 1,300 & 1,670 \\
\hline & Rejects & $\% / \mathrm{Q}$ & 1 & 2 & 2 \\
\hline & Variable costs & EUR/t & 400 & 550 & 650 \\
\hline \multirow{16}{*}{ 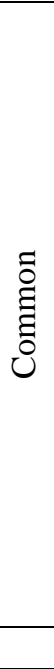 } & Planned production time & $\mathrm{h} /$ year & \multicolumn{3}{|c|}{$8,760.0$} \\
\hline & Operating time of a line & $\mathrm{h} /$ year & \multicolumn{3}{|c|}{$7,332.5$} \\
\hline & Changeover & $\mathrm{x} /$ week & \multicolumn{3}{|c|}{4} \\
\hline & Cleaning and start-up time of the machine & h/one cleaning & \multicolumn{3}{|c|}{2.5} \\
\hline & Repairs and breakdowns & days/year & \multicolumn{3}{|c|}{15} \\
\hline & Number of shifts & day & \multicolumn{3}{|c|}{3} \\
\hline & The length of a shift & $\mathrm{h} / \mathrm{shift}$ & \multicolumn{3}{|c|}{8} \\
\hline & Fixed costs personal ( $2 \%$ annual increase from year 2$)$ & EUR/year & \multicolumn{3}{|c|}{113,382} \\
\hline & Fixed costs other ( $3 \%$ from investment costs) & EUR/year & \multicolumn{3}{|c|}{43,896} \\
\hline & Depreciation (1. - 4. year) & EUR/year & \multicolumn{3}{|c|}{241,323} \\
\hline & Depreciation $(5 .-6$. year $)$ & EUR/year & \multicolumn{3}{|c|}{229,698} \\
\hline & Depreciation (7. - 8. year) & EUR/year & \multicolumn{3}{|c|}{6,417} \\
\hline & Income tax & $\%$ & \multicolumn{3}{|c|}{21} \\
\hline & Discount rate & $\%$ & \multicolumn{3}{|c|}{3,5} \\
\hline & Investment costs & EUR & \multicolumn{3}{|c|}{$1,463,190$} \\
\hline & Planned NPV & EUR & \multicolumn{3}{|c|}{$1,994,379$} \\
\hline
\end{tabular}

\subsection{Optimization of the production plan - deterministic model}

First, the preliminary production plan is optimized by the GRG method. In this step, deterministic model is built, and the following restrictive conditions and requirements are considered, as follows:

The production quantity $\mathrm{A}$ is at least $700 \mathrm{t}$.

Operating time must not exceed 7,332.5 h/year, i.e. $T_{\text {ef, }}$ where Eq. (6):

$$
T_{e f}=T_{A}+T_{B}+T_{C}
$$

$T_{\mathrm{A}}$ is production time for product $\mathrm{A}, T_{\mathrm{B}}$ production time for product $\mathrm{B}, T_{\mathrm{C}}$ production time for product $\mathrm{C}$ and $T_{\mathrm{ef}}$ operating time of a machine. 
The share of production time $\mathrm{B}$ and $\mathrm{C}$ is min. 0.1 and max. 0.9 of free production time ( $\left.T_{\text {ef(free) }}\right)$ of a machine, which ensures that no product type will be excluded from optimization. $T_{\text {ef(free) }}$ is calculated as follows in Eq. (7):

$$
T_{e f(\text { free })}=T_{e f}-T_{A}
$$

Optimization results and sensitivity analysis are presented in Table II. According to the optimized plan, the production program consists of products A of 700 tons per year and the remaining residual capacity is divided between products $B$ and $C$ in a ratio of 0.1: 0.9.

Table II: Optimization results - deterministic model.

\begin{tabular}{|c|c|c|c|}
\hline Variable & Unit & $\begin{array}{c}\text { Resulting } \\
\text { value }\end{array}$ & $\begin{array}{c}\text { Reduced } \\
\text { transition }\end{array}$ \\
\hline$P_{\mathrm{Ad}}$ & t/year & 700 & -931.08 \\
\hline share $T_{\mathrm{B}}$ & $\mathrm{h} /$ year & 0.1 & $-788,794.55$ \\
\hline share $T_{\mathrm{C}}$ & $\mathrm{h} /$ year & 0.9 & 0 \\
\hline$N P V_{\mathrm{d}}$ & EUR & $2,309,897$ & - \\
\hline
\end{tabular}

Performing optimization, a better production capacity plan was achieved than considered in a preliminary plan. According to a new optimized plan, an enterprise can achieve $N P V_{\mathrm{d}}$ of EUR 2,309,897, thus $16 \%$ higher than the $N P V$ according to the preliminary plan. The shortcoming of this optimization is that all input variables have deterministic character.

\subsection{Optimization of the production program - stochastic model}

Changes in variable costs as well as the turnover of market prices can fundamentally affect the reality of achieving investment efficiency. In addition, the probability of achieving this yield is affected by time variables and other cost items with fixed characteristics. Production $\mathrm{C}$ is relatively the most profitable, but the cash flow based on sales features the highest uncertainty. That's influenced by:

- product $\mathrm{C}$ price variability in the market,

- varying height of variable printing costs (depending on the printed theme there is a different need for quantity and type of colour).

In the next step, a probability distribution is defined for each of the versatile input variables. In Table III, there are the distributions and characteristics for the input variables.

The Deterministic model of the preliminary plan, supplemented by probability distributions for the input variables, was subsequently simulated by Monte Carlo simulation and optimized with OptQuest tool. The simulation and optimization process consisted of the following steps:

- Monte Carlo simulation - NPV forecast of the preliminary plan (see Fig. 2),

- production optimization with the OptQuest tool,

- initially planned production volumes in the model are replaced by the best optimization results,

- subsequent Monte Carlo simulation - prognosis for an optimized production plan.

The goal of optimization is to determine the product volumes A, B, C in order to maximize the $N P V$ while maintaining the required production conditions. Due to that fact, optimization parameters were determined as follows:

- Objective: maximization of the mean $N P V$.

- Constraints: the operation time $\left(T_{\mathrm{A}}+T_{\mathrm{B}}+T_{\mathrm{C}}\right)$ may not exceed 7,332.5 $\mathrm{h}$, the sum of $T_{\mathrm{ef}(\mathrm{free})}$ for production $\mathrm{B}$ and $\mathrm{C} \leq 1$.

- Requirements: the risk reduction requirements were not specified. 
- Decision variables (see Table IV): production quantity A $\left(P_{\mathrm{As}}\right)$, time share of $T_{\text {ef (free) }}$ for production B, time share of $T_{\text {ef (free) }}$ for production C.

- Simulation runs with Monte Carlo 10,000.

- Optimization experiments with OptQuest 1,000.

Table III: Distributions for input variables.

\begin{tabular}{|c|c|c|c|}
\hline Variable & Unit & Statistical characteristics & $\begin{array}{c}\begin{array}{c}\text { Distribution } \\
\text { function }\end{array} \\
\end{array}$ \\
\hline \multicolumn{4}{|c|}{ Revenue Variables } \\
\hline Price A & EUR/t & Likeliest 1000; Min. 900; Max. 1100 & Triangular \\
\hline Price B & $\mathrm{EUR} / \mathrm{t}$ & Likeliest 1300; Min. 1170; Max. 1430 & Triangular \\
\hline Price $\mathrm{C}$ & EUR/t & Likeliest 1670; Min. 1400; Max. 1900 & Triangular \\
\hline \multicolumn{4}{|c|}{ Cost Variables } \\
\hline Variable Costs A & EUR/t & Likeliest 400; Min. 360; Max. 440 & Triangular \\
\hline Variable Costs B & EUR/t & Likeliest 550; Min. 495; Max. 605 & Triangular \\
\hline Variable Costs C & EUR/t & Likeliest 650; Min. 510; Max. 755 & Triangular \\
\hline Rejects A & coeff. & Mean 0.01; Std. Dev. 0.001 & Normal \\
\hline Rejects B & coeff. & Mean 0.02; Std. Dev. 0.002 & Normal \\
\hline Rejects C & coeff. & Mean 0.02; Std. Dev. 0.002 & Normal \\
\hline Investment costs & EUR & $\begin{array}{c}\text { Likeliest 1,339,690; Min. 1,205,700; } \\
\text { Max. 1,473,600 }\end{array}$ & Triangular \\
\hline Other Fixed Costs & EUR & Mean 123,500; Std. Dev. 8,973 & Normal \\
\hline \multicolumn{4}{|c|}{ Time Variables } \\
\hline Average Production Time A & $\mathrm{h} / \mathrm{t}$ & Mean 6; Std. Dev. 0.2 & Normal \\
\hline Average Production Time B & $\mathrm{h} / \mathrm{t}$ & Mean 8.5; Std. Dev. 0.4 & Normal \\
\hline Average Production Time C & $\mathrm{h} / \mathrm{t}$ & Mean 7.5; Std. Dev. 0.3 & Normal \\
\hline Machine Cleaning & $\mathrm{h} /$ cleaning & Likeliest 2.5; Min. 1.5; Max. 3.5 & Triangular \\
\hline Machine Repairs & day/year & Mean 15; Std. Dev. 1.5 & Normal \\
\hline Format Changing & times/week & $\begin{array}{l}\text { Value 3; Probability } 0.2 \\
\text { Value 4; Probability } 0.5 \\
\text { Value 5; Probability } 0.2 \\
\text { Value 6; Probability } 0.1\end{array}$ & Discrete \\
\hline
\end{tabular}

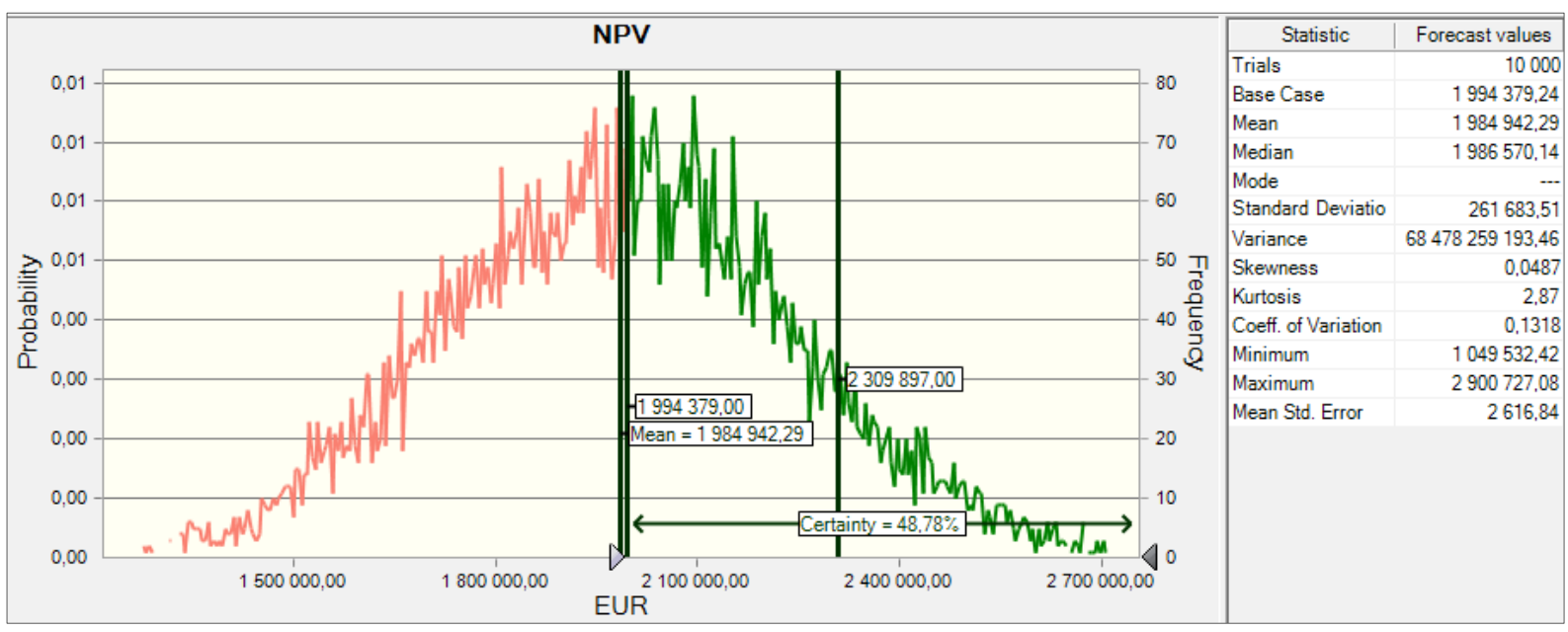

Figure 2: $N P V$ forecast chart (preliminary plan).

The optimization results are presented in Fig. 3 and Table IV. The statistical characteristics of the Monte Carlo simulation for the optimized solution are presented in Table V. 
Table IV: Parameter settings for decision variables.

\begin{tabular}{|c|c|c|c|c|c|}
\hline Decision variables & Lower bound & Base case & Upper bound & Type & Step \\
\hline$P_{\text {As }}$ & 700 & 700 & 1,000 & Discrete & 1 \\
\hline B_share of $T_{\text {eff(ree) }}$ & 0.1 & 0.5 & 0.9 & Continuous & \\
\hline C_share of $\mathrm{T}_{\text {eff(ree) }}$ & 0.1 & 0.5 & 0.9 & Continuous & \\
\hline
\end{tabular}

Table V: Results from OptQuest.

\begin{tabular}{|c|c|c|}
\hline Objectives & \multicolumn{2}{|c|}{ Best Solution } \\
\hline Maximize the mean of $N P V_{\mathrm{s}}$ & \multicolumn{2}{|c|}{$2,301,105$} \\
\hline Constraints & Left Side & Right Side \\
\hline$T_{\mathrm{A}}+T_{\mathrm{B}}+\mathrm{T}_{\mathrm{C}} \leq 7,332.5$ & $7,131.03$ & $7,332.00$ \\
\hline $\mathrm{B}+\mathrm{C}$ share of $T_{\text {effree }} \leq 1$ & 1.00 & 1.00 \\
\hline Decision variables & \multicolumn{2}{|c|}{ Best Solution } \\
\hline $\mathrm{B}_{-}$share of $T_{\text {eff(ree }}$ & \multicolumn{2}{|c|}{0.10} \\
\hline $\mathrm{C}_{-}$share of $T_{\text {eff(ree) }}$ & \multicolumn{2}{|c|}{0.90} \\
\hline$P_{\mathrm{As}}$ & \multicolumn{2}{|c|}{700.00} \\
\hline
\end{tabular}

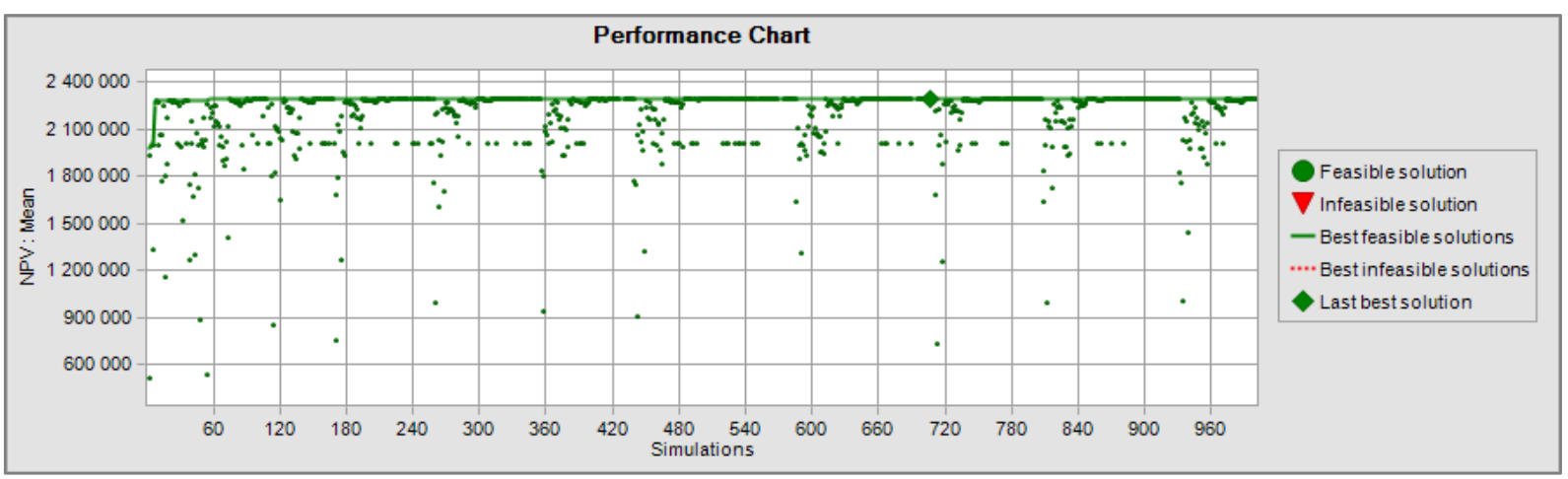

Figure 3: OptQuest chart.

The output based on OptQuest program, as an optimal solution, resulted in reduction of production $\mathrm{A}$ to the required minimum $(700 \mathrm{t})$ and to divide the free capacity in a ratio of 0.1 for product B and 0.9 for product $\mathrm{C}$ (see Table V). However, this solution is the same as in the deterministic model, yet due to the fact that it is based on probability characteristics of the input variables; its statistical profile reveals the risk aspects of this solution. The mean $N P V_{\mathrm{s}}$ (EUR 2,301,105) is comparable to the value $N P V_{\mathrm{d}}$ calculated in the deterministic model (EUR 2,309,897), but the standard deviation of EUR 336,517 points to the uncertainty, that is risk of achieving such result. The probability of achieving profitability in the range of approximately EUR $1,964,000-2,638,000$ is $68 \%$ (mean $\pm \sigma$ ). Compared to the preliminary plan, the assumption of achieving NPV greater than EUR 1,994,379 (planned NPV) is about $81 \%$ (see Fig. 4).

\subsection{Risk management by adjusting the production plan}

Risk analysis focuses on risk management options for optimizing the production plan. In the case of an unacceptable level of risk (in our case, the risk will be the standard deviation of the $N P V_{\text {s }}$ forecast), when optimizing it is necessary to define the level of acceptable $\sigma$. To reduce the risk of return on investment, the production plan needs to be adjusted precisely by limiting the impact of input variables with high uncertainty, which in our case means increasing production of the products $\mathrm{A}$ and $\mathrm{B}$ at the expense of production $\mathrm{C}$, which is although more profitable, but the uncertainty of both, price and cost is relatively high. In order to increase the accuracy of $N P V_{\mathrm{s}}$ forecast, we reduced gradually the standard deviation by about $5,10,15$ and $20 \%$ in the next process and optimized the production plan with this requirement. 


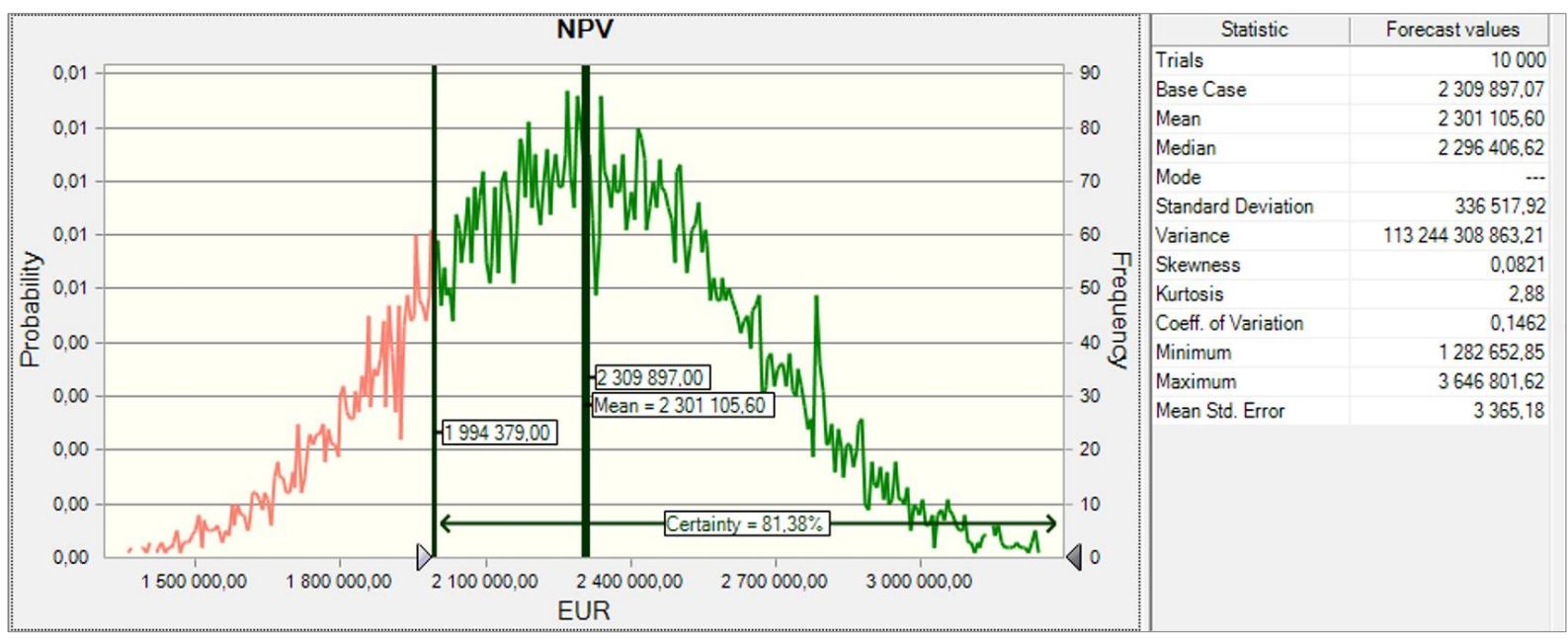

Figure 4: $N P V_{\mathrm{s}}$ forecast chart (optimized plan).

Modification of optimization conditions obviously leads not only to the adjustment of the production plan, but also to lower mean $N P V$ values. The optimization results for the different $\sigma$ levels are shown in Table VI.

Based on the optimization results, the risk reduction of the $N P V_{\mathrm{s}}$ forecast by $5 \%$ is mainly ensured by an increase in production $\mathrm{A}$. The remaining residual capacity is split among production $\mathrm{B}$ and $\mathrm{C}$ in approximately the same proportion as in the original optimized plan. Further reduction of risk (mainly by 15 and $20 \%$ ) is ensured by increasing the share of production $\mathrm{B}$ at the expense of production $\mathrm{C}$, production $\mathrm{A}$ is at the level of the required minimum (see Table VI).

Table VI: Optimization results for reduced risk levels.

\begin{tabular}{|c|c|c|c|c|c|c|c|}
\hline Risk reduction & Requirements & Objective & \multicolumn{3}{|c|}{ Share of $\boldsymbol{T}_{\text {ef (free) }}$} & \multicolumn{3}{|c|}{ Planned production } \\
\hline $\begin{array}{c}\text { \% of standard } \\
\text { deviation }\end{array}$ & $\begin{array}{c}\text { Max. standard } \\
\text { deviation } \\
\text { (EUR) }\end{array}$ & $\begin{array}{c}\text { Maximize the } \\
\text { mean of } \boldsymbol{N P}_{\mathbf{s}^{\prime}} \\
(\text { EUR) }\end{array}$ & $\mathbf{B}$ & $\mathbf{C}$ & $\begin{array}{c}\mathbf{A} \\
(\mathrm{t})\end{array}$ & $\begin{array}{c}\text { B } \\
(\mathrm{t})\end{array}$ & $\begin{array}{c}\boldsymbol{C} \\
(\mathrm{t})\end{array}$ \\
\hline 0 & 336,517 & $2,301,105$ & 0.10 & 0.90 & 700 & 37 & 375 \\
\hline$\sim 5$ & 320,000 & $2,189,212$ & 0.11 & 0.89 & 803 & 32 & 298 \\
\hline$\sim 10$ & 300,000 & $2,126,308$ & 0.25 & 0.75 & 785 & 77 & 262 \\
\hline$\sim 15$ & 285,000 & $2,059,536$ & 0.40 & 0.60 & 700 & 147 & 250 \\
\hline$\sim 20$ & 270,000 & $2,018,816$ & 0.53 & 0.47 & 700 & 173 & 221 \\
\hline
\end{tabular}

\subsection{Risk management by reducing uncertainty of input variables}

Another way reducing the risk of the $N P V_{\mathrm{s}}$ forecast is to limit the uncertainty of the adjustable input variables. Such a magnitude is e.g. the cost of production, or some of the cost factors. A useful tool in this case is a sensitivity analysis that points to variables whose uncertainty reflected most on output uncertainty. There is, in Table VII presented a sensitivity analysis of an optimized plan that lists the impact of uncertainties of the strongest assumption on the total uncertainty of $N P V_{\mathrm{s}}$. In the case of an optimized plan, the uncertainty of the production price $\mathrm{C}$ (as factor $1^{\text {st }}$ in order) and next the production price $\mathrm{A}$ (factor $2^{\text {nd }}$ in order) have the strongest impact on the forecast reliability. They are also the factors with the strongest positive correlation to the output $N P V_{\mathrm{s}}$, which means that the changes in the values of above mentioned inputs most influence the $N P V_{\mathrm{s}}$ value.

In case of the uncertainty limitations of the strongest assumptions - production prices $\mathrm{A}$ and $\mathrm{C}$ ( $p_{\mathrm{A}}$ and $p_{\mathrm{C}}$ ), we would also be able to maintain the production volumes according to the optimized plan and positively affect the total output uncertainty, hence the risk. 
Table VII: $N P V_{\mathrm{s}}$ sensitivity analysis - 10 first assumptions (optimized plan).

\begin{tabular}{|c|c|c|}
\hline Assumptions & $\begin{array}{c}\text { Contribution to } \\
\text { variance }(\%)\end{array}$ & $\begin{array}{c}\text { Rank correlation } \\
(\%)\end{array}$ \\
\hline Price C & 39.1 & 0.61 \\
\hline Price A & 21.8 & 0.46 \\
\hline Variable Costs C & 9.4 & -0.30 \\
\hline Average Production Time A & 7.0 & -0.26 \\
\hline Average Production Time C & 6.0 & -0.24 \\
\hline Format Changing & 5.8 & -0.24 \\
\hline Invested Capital & 3.4 & -0.18 \\
\hline Machine Cleaning & 3.3 & -0.18 \\
\hline Variable Costs A & 2.8 & -0.17 \\
\hline Machine Repairs & 1.0 & -0.10 \\
\hline
\end{tabular}

In the next analysis there were examined, at first step the impacts of the individual symmetric decrease in the price $\mathrm{C}$ uncertainty by $5,10,15$ and $20 \%$ (i.e. the mean value would not change; max. and min. value would change about a given percentage), and at second step the actual price restriction $p_{\mathrm{A}}$ and $p_{\mathrm{C}}$ by $5,10,15$ and $20 \%$. The effect of this change is followed by the indicators of $\sigma$ and mean $N P V_{s}^{\prime \prime}$. For each change, 50 simulation runs were performed, and then evaluated with ANOVA analytic tools. Table VIII lists the arithmetic mean of values $\sigma$ and mean $N P V_{\mathrm{s}}^{\prime \prime}$. Based on the simulation evaluation, we can say that the fall in price uncertainty has an effect on the reduction of the standard deviation, but the value $N P V_{\mathrm{s}}$ does not affect. These relationships were verified by ANOVA analysis and are also evident from the boxplot in Fig. 5. In the case of a standard deviation, there was a statistically significant change in $\sigma(p<0.05)$, but the difference between the mean $N P V_{\mathrm{s}}$ values is not statistically significant $(p>0.05)$.

Table VIII: Impacts of uncertainty changes $p_{\mathrm{A}}$ and $p_{\mathrm{C}}$ on standard deviation and $N P V_{\mathrm{s}}^{\prime \prime}$.

\begin{tabular}{|c|c|c|c|c|c|c|}
\hline \multirow[b]{2}{*}{$\begin{array}{l}\text { Uncertainty } \\
\text { variation }\end{array}$} & \multicolumn{2}{|r|}{$\sigma$} & \multirow[b]{2}{*}{$p$-value } & \multicolumn{2}{|c|}{ Mean $N P V_{s}^{\prime}$} & \multirow[b]{2}{*}{$p$-value } \\
\hline & $\begin{array}{c}\text { Value } \\
\text { (EUR) }\end{array}$ & $\begin{array}{c}\text { Variation } \\
(\%)\end{array}$ & & $\begin{array}{l}\text { Value } \\
\text { (EUR) }\end{array}$ & $\begin{array}{c}\text { Variation } \\
(\%)\end{array}$ & \\
\hline \multicolumn{7}{|l|}{$p_{\mathrm{C}}$} \\
\hline $5 \%$ & 326,918 & -1.66 & \multirow{4}{*}{0.0000} & $2,298,782$ & -0.01 & \multirow{4}{*}{0.0885} \\
\hline $10 \%$ & 318,943 & -4.06 & & $2,297,140$ & -0.08 & \\
\hline $15 \%$ & 315,738 & -5.02 & & $2,299,329$ & +0.02 & \\
\hline $20 \%$ & 311,202 & -6.39 & & $2,298,274$ & -0.03 & \\
\hline \multicolumn{7}{|l|}{$p_{\mathrm{A}} \wedge p_{C}$} \\
\hline $5 \%$ & 321,260 & -3.36 & \multirow{4}{*}{0.0000} & $2,296,368$ & -0.11 & \multirow{4}{*}{0.3164} \\
\hline $10 \%$ & 312,019 & -6.14 & & $2,295,479$ & -0.15 & \\
\hline $15 \%$ & 303,553 & -8.69 & & $2,295,971$ & -0.13 & \\
\hline $20 \%$ & 294,412 & -11.44 & & $2,295,540$ & -0.10 & \\
\hline
\end{tabular}

\section{CONCLUSION}

Enterprises strive to achieve high investment efficiency and quick returns, what assumes the use of investment that will deliver at the same time the highest possible and the most reliable incomes. In case of diverse production, which requires different financial and time costs, and whose yields are even determined by various factors, planning a product mix is a complex process. 


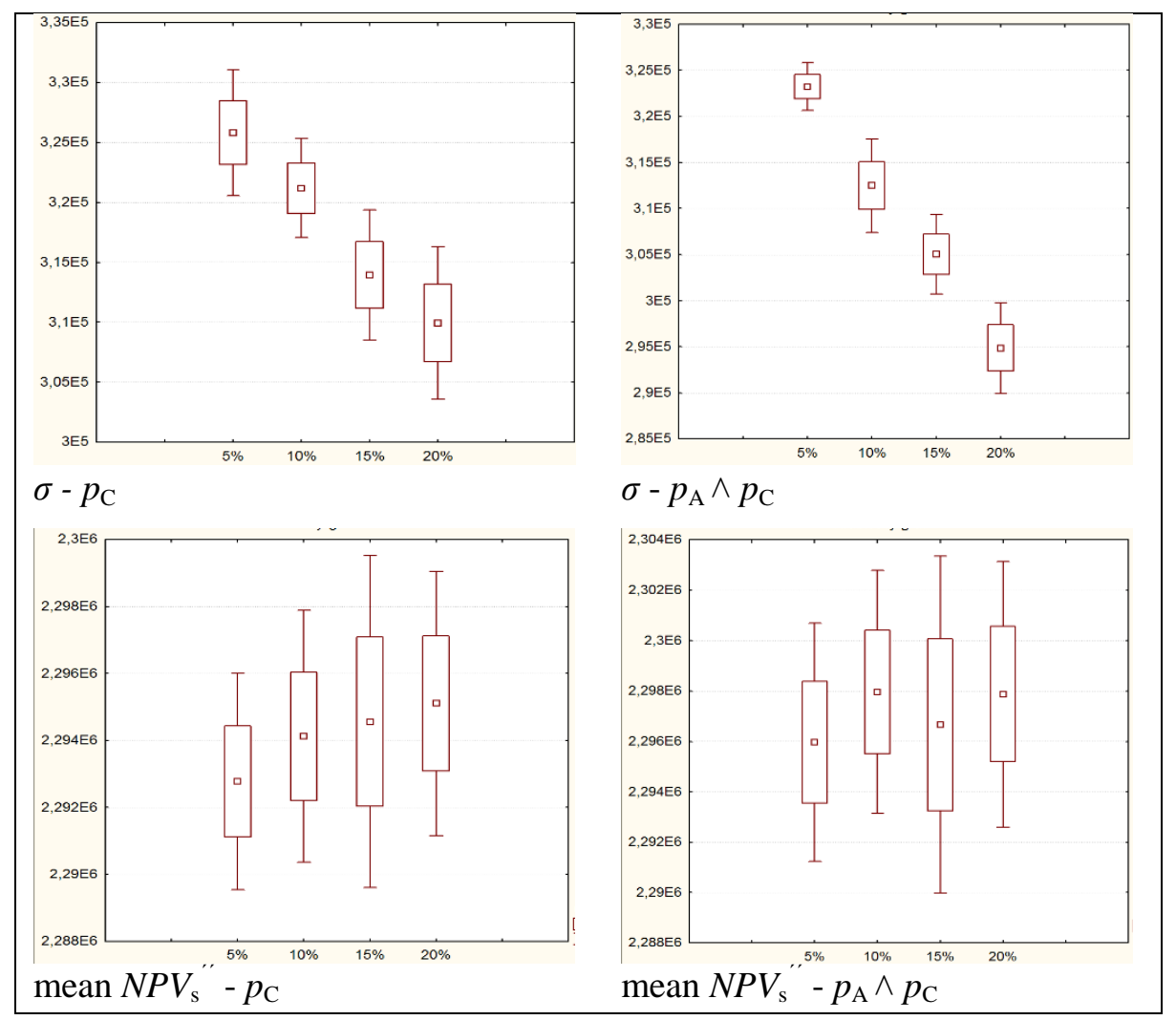

Figure 5: Boxplot $(\bar{x} \pm 1,96 \sigma)$ for $\sigma$ and mean $N P V_{\mathrm{s}}^{\prime \prime}$.

The aim of this paper was to present a comprehensive approach to optimizing diverse production in order to maximize the economic efficiency of the investment. Economic efficiency was monitored by the $N P V$ indicator. In the contribution presented, the optimized model considers both the deterministic and the stochastic nature of the input variables and the implementation of risk in decision making. Optimization was accomplished through two different approaches, which principles and results were mutually compared. According to the first approach, optimization of production was performed via a deterministic model using the GRG algorithm. The second approach was based on the stochastic model. Stochastic model was obtained from the deterministic model by defining the distributions for input variables. Using the Monte Carlo simulation and OptQuest tool, the production plan was optimized, resulting in a production plan that maximized $N P V$, thus based on the probability character of the input variables.

The optimized production plan was submitted to risk analysis. The level of the standard deviation of the forecast was taken as the risk measure. Two approaches have been demonstrated in order to reduce the rate of risk. The first way was modifying the production plan to increase the reliability of the forecast (Section 3.4). The second approach was limiting the uncertainty of key variables (Section 3.5). Based on the sensitivity analysis, the results of which were shown in Table VII, adjustable input variables with significant impact on the total uncertainty of the forecast were identified. Adjusting the uncertainty of the input variables, the impact on the output uncertainty and also the output value was monitored. The significance of these impacts was statistically investigated through the ANOVA analysis. Both approaches offer only a way to reduce the risk. In terms of accuracy of the results, it is not possible to compare each other. They apply a different principle, and, mainly the reliability of the second way is determined by the accuracy of the assumptions.

The presented decision-making approach, taking into account real conditions and risks, is applicable not only to production planning but also to any decision-making tasks. In practice, 
the usual simplification of the decision-making process, by not considering actual developments or changing variables, leads to incorrect decisions and, in the case of investment projects, to high losses of the enterprise. Improving the reliability of forecasts and the quality of management decisions requires incorporating dynamics into the decision making process as well. This is a great help for science and practice using simulation techniques, the use of which becomes more accessible through the increasing possibilities of information-communication technology.

The limits of the presented work consist of some simplifications in defining the problem and creating a mathematical $N P V$ model. Input uncertainties were determined only by estimation based on experience and also did not consider the uncertainty of demand, which in real terms is a stochastic variable similarly like a price. In order to increase the reliability of the forecast, it is appropriate that, in the case of available historical data, uncertainties are also defined using quantitative forecasting methods. Therefore, the next research on this issue will be directed to the possibilities of using simulations and quantitative forecasting methods in addressing optimization tasks towards enterprise management.

\section{ACKNOWLEDGEMENT}

This work has been supported by grant projects VEGA No. 1/0708/16, VEGA No. 1/0063/16, KEGA No. 018TUKE-4/2016 and KEGA No. 029TUKE-4/2016.

\section{REFERENCES}

[1] Fahimnia, B.; Farahani, R. Z.; Marian, R.; Luong, L. (2013). A review and critique on integrated production-distribution planning models and techniques, Journal of Manufacturing Systems, Vol. 32, No. 1, 1-19, doi:10.1016/j.jmsy.2012.07.005

[2] de Sampaio, R. J. B.; Wollmann, R. R. G.; Vieira, P. F. G. (2017). A flexible production planning for rolling-horizons, International Journal of Production Economics, Vol. 190, 31-36, doi:10.1016/j.ijpe.2017.01.003

[3] Bozek, P.; Nikitin, Y.; Bezak, P.; Fedorko, G.; Fabian, M. (2015). Increasing the production system productivity using inertial navigation, Manufacturing Technology, Vol. 15, No. 3, 274278

[4] Kongchuenjai, J.; Prombanpong, S. (2017). An integer programming approach for process planning for mixed-model parts manufacturing on a CNC machining center, Advances in Production Engineering \& Management, Vol. 12, No. 3, 274-284, doi:10.14743/apem2017.3.258

[5] Chou, Y.-C.; Hong, L.-H. (2000). A methodology for product mix planning in semiconductor foundry manufacturing, IEEE Transactions on Semiconductor Manufacturing, Vol. 13, No. 3, 278-285, doi:10.1109/66.857936

[6] Panda, A.; Jurko, J.; Pandova, I. (2016). Monitoring and Evaluation of Production Processes, $1^{\text {st }}$ edition, Springer International Publishing, Cham

[7] Chung, S.-H.; Lee, A. H. I.; Pearn, W. L. (2005). Product mix optimization for semiconductor manufacturing based on AHP and ANP analysis, The International Journal of Advanced Manufacturing Technology, Vol. 25, No. 11-12, 1144-1156, doi:10.1007/s00170-003-1956-8

[8] Tanhaei, F.; Nahavandi, N. (2013). Algorithm for solving product mix problem in two-constraint resources environment, The International Journal of Advanced Manufacturing Technology, Vol. 64, No. 5-8, 1161-1167, doi:10.1007/s00170-012-4054-y

[9] Aryanezhad, M. B.; Komijan, A. R. (2004). An improved algorithm for optimizing product mix under the theory of constraints, International Journal of Production Research, Vol. 42, No. 20, 4221-4233, doi: $10.1080 / 00207540410001695961$

[10] Amin Badri, S.; Ghazanfari, M.; Shahanaghi, K. (2014). A multi-criteria decision-making approach to solve the product mix problem with interval parameters based on the theory of constraints, The International Journal of Advanced Manufacturing Technology, Vol. 70, No. 5-8, 1073-1080, doi: $\underline{10.1007 / \mathrm{s} 00170-013-5360-8}$ 
[11] Escudero, L. F.; Kamesam, P. V.; King, A. J.; Wets, R. J.-B. (1993). Production planning via scenario modelling, Annals of Operations Research, Vol. 43, No. 6, 309-335, doi:10.1007/ BF02025089

[12] Smith, J. S. (2003). Survey on the use of simulation for manufacturing system design and operation, Journal of Manufacturing Systems, Vol. 22, No. 2, 157-171, doi:10.1016/S02786125(03)90013-6

[13] Ponsignon, T.; Mönch, L. (2014). Simulation-based performance assessment of master planning approaches in semiconductor manufacturing, Omega; Vol. 46, 21-35, doi:10.1016/j.omega. 2014.01.005

[14] Straka, M.; Malindzakova, M.; Trebuna, P.; Rosova, A.; Pekarcikova, M.; Fill, M. (2017). Application of EXTENDSIM for improvement of production logistics' efficiency, International Journal of Simulation Modelling, Vol. 16, No. 3, 422-434, doi:10.2507/IJSIMM16(3)5.384

[15] Chen, Y. X. (2016). Integrated optimization model for production planning and scheduling with logistics constraints, International Journal of Simulation Modelling, Vol. 15, No. 4, 711-720, doi:10.2507/IJSIMM15(4)CO16

[16] Güçdemir, H.; Selim, H. (2017). Customer centric production planning and control in job shops: A simulation optimization approach, Journal of Manufacturing Systems, Vol. 43, Part 1, 100-116, doi:10.1016/j.jmsy.2017.02.004

[17] Melouk, S. H.; Freeman, N. K.; Miller, D.; Dunning, M. (2013). Simulation optimization-based decision support tool for steel manufacturing, International Journal of Production Economics, Vol. 141, No. 1, 269-276, doi:10.1016/j.ijpe.2012.08.001

[18] Ankenman, B. E.; Bekki, J. M.; Fowler, J.; Mackulak, G. T.; Nelson, B. L.; Yang, F. (2011). Simulation in production planning: An overview with emphasis on recent developments in cycle time estimation, Kempf, K.; Keskinocak, P.; Uzsoy, R. (Eds.), Planning Production and Inventories in the Extended Enterprise, $1^{\text {st }}$ edition, Springer, Boston, 565-591, doi:10.1007/9781-4419-6485-4_19

[19] Vasant, P.; Barsoum, N. (2010). Hybrid pattern search and simulated annealing for fuzzy production planning problems, Computers \& Mathematics with Applications, Vol. 60, No. 4, 1058-1067, doi:10.1016/j.camwa.2010.03.063

[20] Nazari-Shirkouhi, S.; Eivazy, H.; Ghodsi, R.; Rezaie, K.; Atashpaz-Gargari, E. (2010). Solving the integrated product mix-outsourcing problem using the Imperialist Competitive Algorithm, Expert Systems with Applications, Vol. 37, No. 12, 7615-7626, doi:10.1016/j.eswa.2010.04.081

[21] Fedorko, G.; Rosova, A.; Molnar, V. (2014). The application of computer simulation in solving traffic problems in the urban traffic management in Slovakia, Theoretical and Empirical Researches in Urban Management, Vol. 9, No. 3, 5-17

[22] Saderova, J.; Kacmary, P. (2013). The simulation model as a tool for the design of number of storage locations in production buffer store, Acta Montanistica Slovaca, Vol. 18, No. 1, 33-39

[23] Homem-De-Mello, T.; Bayraksan, G. (2014). Monte Carlo sampling-based methods for stochastic optimization, Surveys in Operations Research and Management Science, Vol. 19, No. 1, 56-85, doi:10.1016/j.sorms.2014.05.001

[24] Cai, T.; Wang, S.; Xu, Q. (2015). Monte Carlo optimization for site selection of new chemical plants, Journal of Environmental Management, Vol. 163, 28-38, doi:10.1016/j.jenvman. 2015.08.002

[25] Janekova, J.; Kovac, J.; Onofrejova, D. (2015). Application of modelling and simulation in the selection of production lines, Applied Mechanics and Materials, Vol. 816, 574-578, doi:10.4028/www.scientific.net/AMM.816.574

[26] Scholleova, H. (2009). Investment controlling: How to evaluate investment intentions and manage company investments, $1^{\text {st }}$ edition, Grada Publishing, Praha 